Editorial

\title{
The Constantly Changing Neonatal Health Care Paradigm in California
}

\author{
Reese H. Clark, MD \\ Journal of Perinatology (2002) 22, 623-627 doi:10.1038/sj.jp.7210823
}

\section{INTRODUCTION}

In this month's Journal of Perinatology, Gould et al. ${ }^{1}$ describe the "Expansion of Community-Based Perinatal Care In California." The authors are to be applauded for their careful and fair presentation of the changing neonatal health care paradigm in California.

The presented data demonstrate that neonatal delivery services and the care of very-low-birth-weight (VLBW) neonates have shifted into community neonatal intensive care units (community NICUs, as defined by California Children's Services). Comparing the two periods 1990 to 1991 and 1996 to 1997, community NICUs have gained $20 \%$ of live births and $26 \%$ of the care for VLBW neonates. This gain came at the expense of all other levels of care, namely, regional NICUs, intermediate NICUs, and primary care hospitals. During the time period examined, neonatal mortality rates were similar in community NICUs as compared to regional NICUs, and the neonatal mortality rate for VLBW neonates decreased at all sites of care. However, neonatal mortality rates for VLBW neonates born at intermediate NICUs and primary care hospitals (again, as defined by California Children's Services) were higher than for community and regional NICUs. The authors concluded that efforts to reduce the number of VLBW births at intermediate NICUs and at primary care hospitals remains an important goal of regionalization.

\section{NEONATAL CARE IS CONSTANTLY EVOLVING AND OUTCOMES CONTINUE TO IMPROVE}

Where, how, and by whom care is provided, even to healthy neonates, is constantly changing. ${ }^{2,3}$ In the 1990s, many new therapies were introduced, such as surfactant, ${ }^{4}$ gentler forms of ventilation, ${ }^{5,6}$ inhaled nitric oxide, ${ }^{7,8}$ and better types of nutrition. ${ }^{9}$ Outcomes improved, reflecting a long-term trend. ${ }^{10,11}$ In 1915, more than 100 infants per 1000 live births died in the first year of life. By 1998, the infant mortality rate was 7.2 per 1000 live births ${ }^{11,12}$ and this improvement has, in part, been attributed to advancements in

Pediatrix Medical Group, Inc., 1301 Concord Terrace, Sunrise, FL, USA.

Address correspondence and reprint requests to Reese H. Clark, MD, Pediatrix Medical Group, Inc., 1301 Concord Terrace, Sunrise, FL 33323-2843, USA. neonatal services. ${ }^{11-14}$ In addition, the survival of VLBW infants has continued to improve, particularly for infants weighing $<1000 \mathrm{~g}$ at birth, without increases in major morbidities. ${ }^{15}$ Gould et al. ${ }^{1}$ report similar improvement occurring at all levels of care in California at a time when there has been increased "deregionalization", ${ }^{16-18}$ although deregionalization is disfavored by experts. ${ }^{16-18}$

That the neonatal mortality rate for VLBW neonates has decreased for all levels of neonatal care in California suggests that the shift in location of patients was also accompanied by the movement of appropriate critical care information into the community. Knowledge (maybe even wisdom) has moved from the privileged few to the bedsides of many. That is not to say that everybody can do everything. Neonatal mortality rates are still better at California Children's Services-approved community and regional NICUs than at other levels of care and the evidence presented supports the goal of reducing the number of VLBW neonates born at intermediate NICUs and primary care hospitals. It also appears that certification of units by California Children's Services is associated with improved outcome and this improvement is likely related to the collaborative quality improvement efforts supported by the California Children's Services and the California Perinatal Quality Care Collaborative.

\section{WHERE SHOULD CARE BE PROVIDED?}

It is reasonable to ask, "How much care can be moved out to the community?" This debate is important since more than half of the admissions to NICUs are neonates weighing more than $2 \mathrm{~kg}$ (see Figure 1). Many illnesses (e.g., sepsis, birth depression, meconium aspiration, and pulmonary hypertension) in these larger infants are much less predictable than those associated with prematurity, but most are treatable and often resolve even in the most critically ill neonates. ${ }^{19-22}$ While it is reasonable to set a goal of guaranteeing that every neonate should be born in a hospital with a well-trained neonatal resuscitation team, it is not realistic to anticipate that neonates should be born only in sites with fully trained and experienced ECMO teams. Regionalization of complicated and high-tech services is important.

The challenge is to decide how much and what care can be safely provided in the community compared to the care that should only be provided in regional perinatal centers. This topic is constantly debated as neonatal health care evolves. For example, we have debated by whom and where surfactant should be administered. ${ }^{23}$ There is a continued debate on the role of high-frequency ventilation before 




Figure 1. Numbers (and percentage) of admissions to NICUs managed by Pediatrix Medical Group between 1996 and 2001 by birth weight group.

transport to ECM0 centers, ${ }^{24,25}$ and most recently, the introduction of inhaled nitric oxide has led to new concerns about the dissemination of technology and the potential for further deregionalization of care. ${ }^{26}$ It is unlikely that these debates can be fully resolved.

The corollary question is, "How preventable is the delivery of VLBW neonates at primary care hospitals?" Although there is evidence that maternal transport is better than delivery of the neonate and then transport, ${ }^{27,28}$ some VLBW deliveries are unavoidable. ${ }^{29} \mathrm{~A}$ report from 1991 suggested that $>50 \%$ of mothers who delivered VLBW neonates outside of level three centers may have conditions (precipitous delivery or advance labor, fetal distress, placental abruption, bleeding from a placenta previa, etc.) that are contraindications to transport. ${ }^{29}$ In addition, the medical team may assess the fetus to be previable or nonviable due to anomalies and not offer transport as a medical option. It would be helpful to know how many of the $656 \mathrm{VLBW}$ neonatal deliveries at the 148 (approximately four patients per sites) primary care hospitals were avoidable.

In addition, and as Gould et al. ${ }^{1}$ discuss, it would be helpful to know how many of the VLBW neonates born at intermediate NICUs or primary care hospitals were transferred to higher levels of care. Assigning mortality to the hospital of birth may not be fair in the case where death occurred late and after an adverse event at the accepting hospital. Our goal should be to define the number of preventable deaths.

\section{VARIATION IN OUTCOME}

Just as there are outcome differences between the levels of care, there are equally important differences at any particular level of care. ${ }^{30,31}$ It is known that neonatal mortality rates are not the same, even when risk-adjusted, between diverse higher level care units. ${ }^{30,32,33}$ While improving regionalization for selected services is important, it is equally important to establish open dialogue between units providing the same level of care. Unit practice variation is large and there is plenty of opportunity for ongoing improvement in the care we give. ${ }^{31,33}$

Another important issue surrounds who is providing care at the intermediate and primary care sites. The Organization of Neonatal Training Program Directors has stated that it believes that restriction of time spent by pediatric residents in critical care areas has resulted in a serious deterioration of competence in the care of sick newborn infants among graduating pediatric residents (http://www.aap.org/sections/resgoals.doc). One must be worried that some of the difference in outcomes between primary care hospitals may be related to this deterioration in competency.

However, this does not explain the difference between the intermediate NICUs and the higher levels of care. Most care in these units are provided or supervised by a neonatologist and, in many cases, the same neonatal practice group provides services at local community or regional NICUs. It would be interesting to compare the outcomes of neonates born at intermediate NICUs where: (1) care is provided by neonatal practice groups, which also provide services at high-level care units; or (2) care is provided by neonatal practice groups, which provide services only at intermediate NICUs and primary care hospitals. Does it matter how and by whom the service is provided? Recent data from the nursing literature suggest that it does. ${ }^{34}$

\section{DOES PRACTICE (VOLUME) MAKE PERFECT?}

The number of procedures performed at a hospital (hospital volume) and mortality rates for many surgical procedures are inversely related. ${ }^{35-37}$ Data on the effect of volume in NICUs have been less clear. In California, two studies suggest that NICUs with 
an average daily census of 15 or more neonates had lower neonatal mortality rates. ${ }^{38,39}$ In contrast, a study of 62 NICUs reporting data to the Vermont-0xford network showed that when patient characteristics, volume, and presence of a residency program were evaluated using logistic regression, increased volume (VLBW cases treated) was not associated with decreased mortality risk for VLBW neonates. ${ }^{30}$

Epstein" $^{37}$ suggests that "The imperfect correlation between volume and risk-adjusted mortality reminds us that volume is not an indicator of quality of care. Rather, it is a structural characteristic that is easy to calculate and is often associated with quality. More fundamental factors underlie differences in outcome..." The quality of prenatal care, the choice of treatments offered, the proximity of the NICU to the delivery suite, the composition of the health care team, health processes in the NICU that direct how care is provided, medical judgment and skill, and postdischarge care all influence outcome. Identifying the relative contribution of these diverse factors is and will continue to be a significant challenge. ${ }^{37}$

Insuring that VLBW infants are born at hospitals with adequate experience (volume) is only one step toward improving the quality of care. Reducing the gap in risk-adjusted mortality between highvolume and low-volume NICUs is an equally important objective. Measuring and reporting outcomes will not improve outcomes if not accompanied with an intent to discover the reasons for differences in outcomes and a commitment to implement changes in processes and practice that can improve outcome. ${ }^{40}$

\section{IS NEONATAL MORTALITY FOR VLBW NEONATES A SURROGATE FOR GOOD PERINATAL/NEONATAL CARE?}

We can no longer accept that the neonatal mortality rate is a surrogate for good (or even adequate) perinatal and neonatal care. ${ }^{41}$ Neonatal death is currently a relatively rare event $(<10 \%$ of inborn admissions) and our ability to find "significant" differences between sites is seriously hampered by difficulty in accumulating an adequate site sample size. Even when data are summarized and the pooled sample size is large (as presented in the article by Gould et al. ${ }^{1}$ ), the confidence intervals for the odds ratios are large and range from 0.5 to 2 in some comparisons. Looking at more common events such as weight gain and head growth, which happen to every baby and are surrogates for "health" — may be more useful in discriminating important care differences.

Equally as important is that we must give up our fixation on the extremely-low-birth-weight (ELBW) and VLBW infant. If we plot the proportion of neonates (presented in the Appendix of the data of Gould et al. ${ }^{1}$ ) by birth weight group, the largest number and proportion are neonates weighing between 1000 and $1499 \mathrm{~g}$ (see Figure 2). Almost $60 \%$ of the neonates at every level of care weigh between 1000 and $1499 \mathrm{~g}$. In Table 6 of the article by Gould et al., there is no evidence that birth at a regional NICU is associated with an increase in survival for neonates weighing between 1000 and $1499 \mathrm{~g}$. In fact, the numbers suggest that there may be a slight advantage (not significant) to being born at a community NICU (OR 0.65, CI 0.42-1.02). I agree with Gould et al. ${ }^{1}$ that this may be caused by differences in acuity related to unmeasured confounding variables and a more complex case mix. However, this observation should stimulate further research.

When we examine the Pediatrix Medical Group administrative data set, we find that neonates weighing $<1500 \mathrm{~g}$ represent approximately $17 \%$ of NICU admissions (see Figure 1). The Pediatrix data are similar to a large data set reported from Canada where $20 \%$ of NICU admissions were $\leq 1500 \mathrm{~g}$ birth weight. ${ }^{33}$ In measuring the performance of NICU care, we must evaluate the outcomes of the other $80 \%$ to $83 \%$ of neonates to whom we provide care. Infants $>1500$ g make up almost one-half of all NICU care days and they are no less important. The same practice variations

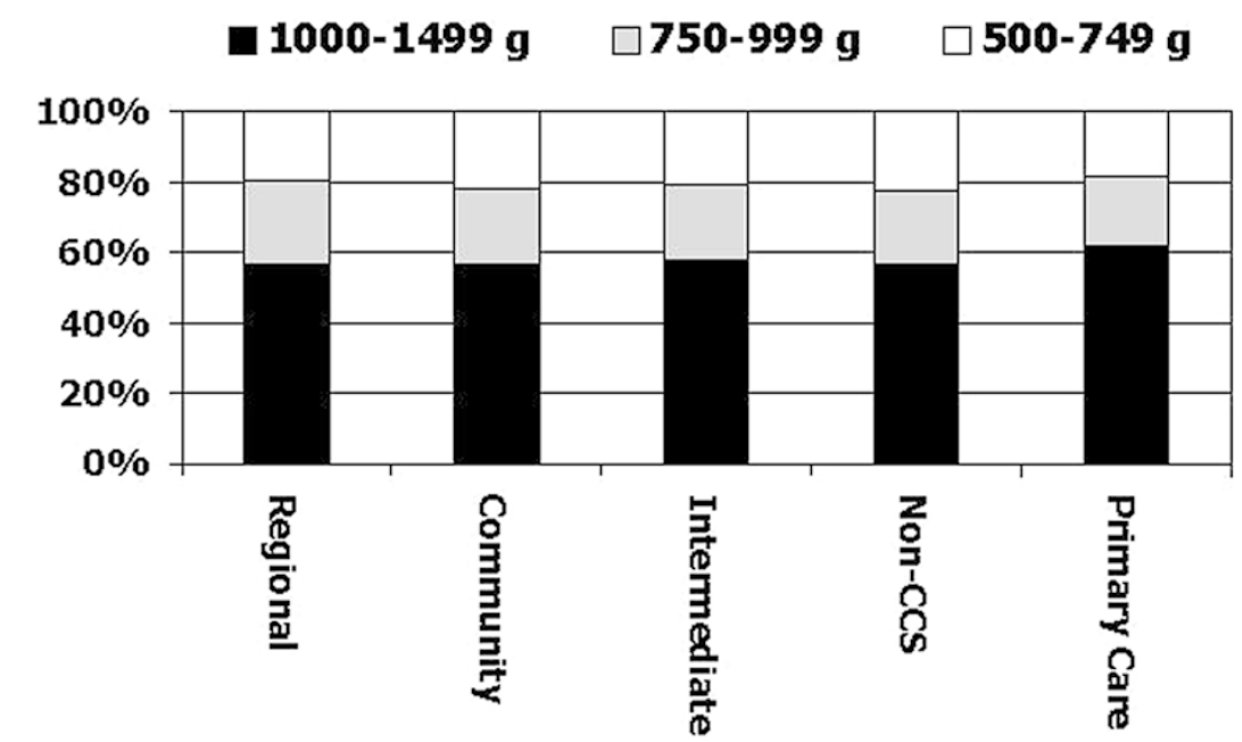

Figure 2. Proportion of neonates in each birth weight subgroup by level of care as reported by Gould et al. ${ }^{1}$ 
and outcome differences found in smaller babies are also seen in bigger babies. ${ }^{42,43}$

\section{WE NEED A MORE REAL-TIME BAROMETER}

Perinatologists and neonatologists provide critically needed care at the beginning of life and the quality of that care impacts the child and the child's family for the rest of their lives. For this reason, we need to develop better real-time efforts to assess outcomes. Summaries presented in several recent papers represent data that are all over 5 years old. ${ }^{15,33,38,39,44}$ It is dangerous to make health care policy decisions based on old data. We need to more completely understand the distribution of care and the outcomes of that care, as it currently exists in 2002. The efforts of the California Perinatal Quality Care Collaborative are extraordinarily valuable and place California and its perinatal community as leaders on collaborative efforts to not only reduce neonatal mortality, but to improve other outcomes as well. Improving information sharing (regionally and locally) is essential and no doctor, mother, father, or newborn should be denied access to strategies for improving health outcomes.

$\mathrm{RHC} / \mathrm{sam}$

Attachments

Conflict of Interest Statement:

Dr Clark is the Director of Research for Pediatrix Medical Group. As of January 2002, Pediatrix provided care in 14 NICUs in California. The breakdown of these NICUs is as follows:

- Regional (1)

- Community, California Children's Services-approved (11)

- Community, non-California Children's Services-approved (0)

- Intermediate (2).

Many of the medical directors employed by Pediatrix participate in the California Perinatal Quality Care Collaborative and agree with the goals outlined in its charter.

\section{References}

1. Gould JB, Marks AR, Chavez G. Expansion of community-based perinatal care in California. J Perinatol 2002;22(8):630-40.

2. Richardson DK, Gray JE, Gortmaker SL, Goldmann DA, Pursley DM, McCormick MC. Declining severity adjusted mortality: evidence of improving neonatal intensive care. Pediatrics 1998;102:893-9.

3. Roy BJ, Rycus P, Conrad SA, Clark RH. The changing demographics of neonatal extracorporeal membrane oxygenation patients reported to the Extracorporeal Life Support Organization (ELSO) Registry. Pediatrics 2000; 106:1334-8.

4. Jobe AH, Ikegami M. Biology of surfactant. Clin Perinatol 2001;28:655-viii.

5. Clark RH, Gerstmann DR, Jobe AH, Moffitt ST, Slutsky AS, Yoder BA. Lung injury in neonates: causes, strategies for prevention, and long-term consequences. J Pediatr 2001;139:478-86.
6. Jobe AH, Ikegami M. Prevention of bronchopulmonary dysplasia. Curr Opin Pediatr 2001;13:124-9.

7. Clark RH, Kueser TJ, Walker MW, et al. Low-dose nitric oxide therapy for persistent pulmonary hypertension of the newborn. Clinical Inhaled Nitric Oxide Research Group. N Engl J Med 2000;342:469-74.

8. The Neonatal Inhaled Nitric Oxide Study Group. Inhaled nitric oxide in term and near-term infants: neurodevelopmental follow-up of the Neonatal Inhaled Nitric 0xide Study Group (NINOS). J Pediatr 2000;136:611-7.

9. Carver JD, Wu PY, Hall RT, et al. Growth of preterm infants fed nutrientenriched or term formula after hospital discharge. Pediatrics 2001;107:6839.

10. Thompson LA, Goodman DC, Little GA. Is more neonatal intensive care always better? Insights from a cross-national comparison of reproductive care. Pediatrics 2002;109:1036-43.

11. Guyer B, Freedman MA, Strobino DM, Sondik EJ. Annual summary of vital statistics: trends in the health of Americans during the 20th century. Pediatrics 2000;106:1307-17.

12. Hoyert DL, Freedman MA, Strobino DM, Guyer B. Annual summary of vital statistics: 2000. Pediatrics 2001;108:1241-55.

13. Kahn DJ, Richardson DK, Gray JE, et al. Variation among neonatal intensive care units in narcotic administration. Arch Pediatr Adolesc Med 1998;152: $844-51$.

14. Guyer B, Hoyert DL, Martin JA, Ventura SJ, MacDorman MF, Strobino DM. Annual summary of vital statistics - 1998. Pediatrics 1999;104:1229-46.

15. Lemons JA, Bauer CR, Oh W, et al. Very low birth weight outcomes of the National Institute of Child Health and Human Development Neonatal Research Network, January 1995 through December 1996. NICHD Neonatal Research Network. Pediatrics 2001;107:E1.

16. Hein HA. Regionalization of perinatal health care: a lesson learned but lost. J Perinatol 1999;19:584-8.

17. Hein HA, Lofgren MA. The changing pattern of neonatal mortality in a regionalized system of perinatal care: a current update. Pediatrics 1999;104: $1064-9$.

18. Yeast JD, Poskin M, Stockbauer JW, Shaffer S. Changing patterns in regionalization of perinatal care and the impact on neonatal mortality. Am J Obstet Gynecol 1998;178:131-5.

19. Bennett CC, Johnson A, Field DJ, Elbourne D. UK collaborative randomised trial of neonatal extracorporeal membrane oxygenation: follow-up to age 4 years. Lancet 2001;357:1094-6.

20. UK Collaborative ECMO Trail Group. UK collaborative randomised trial of neonatal extracorporeal membrane oxygenation. UK Collaborative ECMO Trail Group. Lancet 1996;348:75-82.

21. UK Collaborative ECMO Trail Group. The collaborative UK ECMO (Extracorporeal Membrane 0xygenation) trial: follow - up to 1 year of age. Pediatrics 1998;101:E1.

22. Elbourne D, Field D, Mugford M. Extracorporeal membrane oxygenation for severe respiratory failure in newborn infants. Cochrane Database Syst Rev 2002. CD001340.

23. Mildenhall LF, Pavuluri NN, Bowman ED. Safety of synthetic surfactant use before preterm newborn transport. J Paediatr Child Health 1999;35:530-5.

24. Kinsella JP, Abman SH. Clinical pathophysiology of persistent pulmonary hypertension of the newborn and the role of inhaled nitric oxide therapy. J Perinatol 1996;16:S24-7.

25. Kinsella JP, Truog WE, Walsh WF, et al. Randomized, multicenter trial of inhaled nitric oxide and high-frequency oscillatory ventilation in severe, persistent pulmonary hypertension of the newborn. J Pediatr 1997;131:55-62. 
26. Clark RH. How do we safely use inhaled nitric oxide?. Pediatrics 1999;104: 296-7.

27. Hohlagschwandtner M, Husslein P, Klebermass K, Weninger M, Nardi A, Langer M. Perinatal mortality and morbidity. Comparison between maternal transport, neonatal transport and inpatient antenatal treatment. Arch Gynecol Obstet 2001;265:113-8.

28. Harris TR, Isaman J, Giles HR. Improved neonatal survival through maternal transport. Obstet Gynecol 1978;52:294-300.

29. Menard MK, Liu Q, Holgren EA, Sappenfield WM. Neonatal mortality for very low birth weight deliveries in South Carolina by level of hospital perinatal service. Am J Obstet Gynecol 1998;179:374-81.

30. Horbar JD, Badger GJ, Lewit EM, Rogowski J, Shiono PH. Hospital and patient characteristics associated with variation in 28 -day mortality rates for very low birth weight infants. Vermont 0xford Network. Pediatrics 1997;99:14956.

31. Horbar JD, Rogowski J, Plsek PE, et al. Collaborative quality improvement for neonatal intensive care. NIC/Q Project Investigators of the Vermont Oxford Network. Pediatrics 2001;107:14-22.

32. Sankaran K, Chien LY, Walker R, Seshia M, Ohlsson A. Variations in mortality rates among Canadian neonatal intensive care units. CMAJ Can Med Assoc J 2002;166:173-8.

33. Lee SK, McMillan DD, Ohlsson A, et al. Variations in practice and outcomes in the Canadian NICU network: 1996-1997. Pediatrics 2000;106:1070-9.

34. Needleman J, Buerhaus P, Mattke S, Stewart M, Zelevinsky K. Nurse-staffing levels and the quality of care in hospitals. N Engl J Med 2002;346:171522.
35. Begg CB, Riedel ER, Bach PB, et al. Variations in morbidity after radical prostatectomy. N Engl J Med 2002;346:1138-44.

36. Birkmeyer JD, Siewers AE, Finlayson EV, et al. Hospital volume and surgical mortality in the United States. N Engl J Med 2002;346:1128-37.

37. Epstein AM. Volume and outcome - it is time to move ahead. N Engl J Med 2002;346:1161-4.

38. Cifuentes J, Bronstein J, Phibbs CS, Phibbs RH, Schmitt SK, Carlo WA. Mortality in low birth weight infants according to level of neonatal care at hospital of birth. Pediatrics 2002;109:745-51.

39. Phibbs CS, Bronstein JM, Buxton E, Phibbs RH. The effects of patient volume and level of care at the hospital of birth on neonatal mortality. JAMA 1996;276:1054-9.

40. Horbar JD. The Vermont Oxford Network: evidence-based quality improvement for neonatology. Pediatrics 1999;103:350-9.

41. McCormick MC. The outcomes of very low birth weight infants: are we asking the right questions? Pediatrics 1997;99:869-76.

42. Walsh-Sukys MC, Cornell DJ, Houston LN, Keszler M, Kanto WP Jr. Treatment of persistent pulmonary hypertension of the newborn without hyperventilation: an assessment of diffusion of innovation. Pediatrics 1994; 94:303-6.

43. Walsh-Sukys MC, Tyson JE, Wright LL, et al. Persistent pulmonary hypertension of the newborn in the era before nitric oxide: practice variation and outcomes. Pediatrics 2000;105:14-20.

44. Goodman DC, Fisher ES, Little GA, Stukel TA, Chang CH, Schoendorf KS. The relation between the availability of neonatal intensive care and neonatal mortality. N Engl J Med 2002;346:1538-44. 